\title{
Additive and synergistic interactions amongst Orius laevigatus \\ (Heteroptera: Anthocoridae), entomopathogens and azadirachtin for controlling western flower thrips (Thysanoptera: Thripidae)
}

\begin{abstract}
This study evaluated the efficacy of the foliage-dwelling predator Orius laevigatus, soil applied entomopathogens and azadirachtin alone and in combinations for controlling western flower thrips (WFT). Evaluated products were Nemastar® Steinernema carpocapsae (Enema) and Orius laevigatus (Re-natur), Metarhizium anisopliae isolate ICIPE-69 and NeemAzal-T (azadirachtin) (Trifolio). Efficacy against WFT was significantly improved by combined treatments achieving 62-97\% reduction in WFT emergence, compared to $45-74 \%$ in single treatments, and interactions resulted in two synergistic and eight additive responses. Metharhizium based treatments reduced WFT survival by $93-99.6 \%$ when late mortality by mycosis was considered. Halving the number of released predators did not significantly reduce efficacy (86-96\% vs $76-88 \%$ thrips reduction), and when Orius was introduced to target L1 of WFT, $96-98 \%$ reduction was achieved while only $71-89 \%$ for L2. Early release of $O$. laevigatus and combination with soil application of NeemAzal-T and/or entomopathogens can be a successful and reliable biocontrol strategy for WFT.
\end{abstract}

Key words: Frankliniella occidentalis, integrated biocontrol, Entomopathogenic fungi, Entomopathogenic nematodes, NeemAzal-T solution 


\section{Introduction}

Western flower thrips, Frankliniella occidentalis Pergande (Thysanoptera: Thripidae), is an important pest of ornamentals and vegetables that causes extensive economic losses in greenhouse and open-field plant production (Reitz et al. 2011). Western flower thrips have an affinity to tight/cryptic feeding sites within buds or on rapidly growing tissues such as young leaves and flowers, and this cryptic behaviour is a major challenge because it makes thorough coverage difficult when using insecticides. Moreover, pupation occurs in the soil and a certain part of the population is escaping from plant delivered compounds. In addition, resistance to conventional insecticides has been recorded worldwide (Jensen 2000, Herron and James 2005, Bielza et al. 2007). In addition, there is a global tendency towards reducing the use of synthetic pesticides because of associated problems of resistance, environmental contamination, adverse effects on non-target organisms and demand for pesticide-free foods (Gao et al. 2012). Biocontrol could therefore be a convenient alternative option providing economic and eco-toxicological benefits (Bonsignore and Vacante 2012).

In its life cycle, western flower thrips occur as highly mobile adult, immobile but protected egg in plant tissue as well as first and second larval stage in the crop canopy where it is relatively vulnerable to predatory mites or bugs preferring the same habitat. In contrast, the descending late second larval stage escapes such antagonists to pupate in the soil or leaf litter (Steiner et al. 2011), but tends to be more vulnerable to soil dwelling predators and pathogens (Holmes et al. 2012). Therefore, an ideal biocontrol strategy would target these soil-dwelling stages as well as the foliage-inhabiting adult and larval stages (Rahman et al. 2011).

The Orius spp. (Hemiptera: Anthocoridae) were shown to be effective predators for thrips in both field and greenhouse crops throughout the world as they are the only predators that attack thrips even in cryptic habitats such as flower buds (Blaeser et al. 2004, Silveira et al. 2004, Islam et al. 2010), and can prey on all thrips stages as well as other pests like aphids, 
spider mites, whiteflies and moth eggs. They also feed on pollen, which enables them to build a population in pollen-bearing crops when thrips are not available (Sanchez et al. 2000).

However, there are conflicting reports concerning the success of Orius in controlling western flower thrips. While significant efficacy has been reported in several studies (Silveira et al. 2004, Blaeser et al. 2004, Xu et al. 2006, Bosco et al. 2008, Weintraub et al. 2011) other authors observed only low control of thrips by Orius as compared to other biocontrol agents (Medina et al. 2003, Shipp and Wang 2003, Pozzebon et al. 2015). Therefore, it might be worthwhile to test the release of Orius spp. in combination with additional measures compatible with natural enemies such as botanicals or entomopathogens for efficient and persistent pest suppression. The following are interesting candidates:

Biorational products containing active ingredients such as azadirachtin derived from the neem tree Azadirachta indica A. Juss, Meliaceae and often termed simply as neem products are general-purpose botanical pesticides today widely used in different crops, in particular in organic production systems (Islam et al. 2010). They have multiple mechanisms of action (Mitchell et al. 2004) and hence low risk for selection of resistant pest biotypes, and extremely low toxicity to humans and often with relatively high selectivity concerning natural enemies if direct contamination of sensitive stages is avoided. They can be used in combinations with entomopathogens that are "compatible" (causing mortality $<20 \%$ ) and their joint efficacy can potentially benefit from synergistic interaction (Mohan et al. 2007, Islam et al. 2010). However, since the active ingredient azadirachtin is susceptible to photodegradation by UV radiation, soil application is advantageous to minimize exposure to sunlight, and for soil treatments water based formulations of azadirachtin have been proven to be most efficient in controlling pests (Thoeming et al. 2006, Karanja et al. 2015)

Entomopathogenic fungi (EPF) such as Metarhizium anisopliae (Metschnikoff) Sorokin (Hypocreales: Clavicipitacea) has also been described as an efficient biocontrol agents against western flower thrips (Ansari et al. 2007, 2008). The relative safety and specificity of these 
fungal pathogens may enhance their acceptance for use in pest management programs (Gao et al. 2012). However, their need for very specific conditions such as high relative humidity (RH) and temperature as well as short persistence of conidia under high UV light favour their use in the soil where thrips mostly pupate which is a more convenient microclimatic environments for fungal infection (Cloyd 2009). Susceptibility of thrips to soil treatment with Metarhizium anisopliae has already been shown (Brownbridge 2006, Skinner et al. 2012, Otieno et al. 2016).

Another option is to use entomopathogenic nematodes (EPNs) such as Steinernema carpocapsae (Rhabditida: Steinernematidae). In above-ground application the efficacy of EPNs is limited due to their sensitivity to desiccation and UV radiation (Shapiro-Ilan et al. 2010), however they were found to be suited for infecting the cryptic pupal stages of western flower thrips in the soil, and efficiently reducing thrips emergence when drenched into the soil at high rates to compensate for limited dispersal capacity (Premachandra et al. 2003a, 2003b; Buitenhuis and Shipp 2005, Ebssa et al. 2006, Otieno et al. 2016). The EPNs applied to the soil can be combined without any detrimental interaction with other biocontrol agents, in particular foliage-dwelling predators of thrips. A detailed study of the interaction among various combinations of entomopathogens and azadirachtin targeting the soil stages of western flower thrips in a microcosm experiment was reported by Otieno et al. (2016). In addition to that, the present study includes $O$. laevigatus as a control agent, with the aim of assessing the efficacy of biocontrol agents that possibly could act in combination above and below ground for integrated thrips management. We evaluated basically the effect of releasing O. laevigatus, combined with soil application of NeemAzal-T, S. carpocapsae and $M$. anisopliae, against western flower thrips. A detailed economic valuation is however beyond the scope of this study. 


\section{Materials and Methods}

Host plant and western flower thrips rearing: Two-week old bean seedlings (Phaseolus vulgaris L. var. 'Speedy') seedlings were used as host plants. Individual seedlings were transplanted into $16 \mathrm{~cm}$ diameter plastic pots filled with $600 \mathrm{~g}$ of commercial substrate (CS) Fruhstorfer Erde, type P (Archut GmbH, Lauterbach-Wallenrod, Germany); $50 \%$ peat, $35 \%$ clay, $15 \%$ humus; $\mathrm{pH}$ 5.7-6.3; 124-185 mg N, 120-179 mg $\mathrm{P}_{2} \mathrm{O}_{5}, 190-284 \mathrm{mg} \mathrm{K} \mathrm{O}_{2}$ and 0.8$1.4 \mathrm{~g} \mathrm{KCL}$ salt content per L. The seedlings were kept under greenhouse conditions of $22 \pm 2$ ${ }^{\circ} \mathrm{C}, 65$ - $75 \% \mathrm{RH}$ and a 16:8 h light: dark photoperiod. To obtain thrips of the same age, synchronized rearing of western flower thrips was established on pods of French beans in 0.75 litre glass jars (Leifheit, Nassau, Germany) according to a protocol by Berndt et al. (2004).

Predatory bug: Orius laevigatus were provided by Re-natur (Stolpe, Germany) in bottles containing 500 individuals dispersed in vermiculite, and were released within one day after receipt.

Entomopathogenic fungi (EPF): Metarhizium anisopliae ICIPE-69 commercialized strain by International Centre of Insect Physiology and Ecology (Kenya) with identification characteristics stated in Niassy et al. (2012) was obtained as dry conidia and stored at $4{ }^{\circ} \mathrm{C}$. Before use, an infection cycle was run on western flower thrips adults to ensure virulence to that target. Conidia from infected WFT cadavers were isolated onto potato dextrose agar media (PDA), supplemented with peptone and yeast extract. Two week old fungal cultures maintained at $25{ }^{\circ} \mathrm{C}$ and grown on artificial media less than three times after isolation from WFT were used for the experiments. An aqueous conidial suspension was then prepared by scraping off dried conidia from the PDA plates and mixing with $0.05 \%$ Tween 80 . The conidial suspension was then adjusted to $10^{7}$ conidia per $100 \mathrm{ml}$ (Islam et al. 2010) using a Fuchs-Rosenthal haemocytometer (Marienfeld GmbH \& Co. KG, Lauda Königshofen, Germany) and a compound microscope (x400 magnification) (Goettel and Inglis 1997). 
Viability of conidia was assessed before the experiments to adjust the desired concentration of viable conidia per $\mathrm{ml}$ for every bioassay, details of the procedure are described in Otieno et al. (2016).

Entomopathogenic nematodes (EPNs): Nemastar® based on S. carpocapsae was obtained as a clay formulation from e-nema $\mathrm{GmbH}$ (Raisdorf, Germany) and stored at $4{ }^{\circ} \mathrm{C}$ until use. Before exposure to western flower thrips, nematodes were allowed to acclimatize at ambient room temperature for four hours. Thereafter, $1 \mathrm{~g}$ of the product was dissolved in $50 \mathrm{ml}$ of deionized water, and $1 \mathrm{ml}$ of the suspension was mounted on a microscope slide to assess EPN density and mobility. A final concentration of about 80,500 infective juveniles (IJ) in $25 \mathrm{ml}$ of de-ionized water was prepared by quantification and dilution giving a concentration of $400 \mathrm{IJ}$ per $\mathrm{cm}^{2}$ soil per experimental pot (Premachandra et al. 2003b).

NeemAzal-T: NeemAzal-T solution (1\% active ingredient of azadirachtin dissolved in water) was obtained from Trifolio-M GmbH (Lahnau, Germany). A concentration of $1 \mathrm{ml} / \mathrm{kg}$ of substrate was used. For each pot (600 mg of the substrate Fruhstorfer Erde), $0.6 \mathrm{ml}$ of the basic solution was diluted in $100 \mathrm{ml}$ de-ionized water. The suspension was shaken for 30 minutes in a mechanical shaker before application.

General experimental procedure: Male and female Orius were isolated in a plastic bottle prior to the experiments. Only females were used since they are generally larger and feed more for reproduction (Xu et al. 2006). Each experimental unit consisted of a potted bean plant in a plastic pot $(16 \mathrm{~cm}$ diameter) enclosed by a plexiglass cylinder (diameter $15 \mathrm{~cm}$, height $40 \mathrm{~cm}$ ) serving as tightly fitting microcosm. Proper ventilation was ensured by the open top and four additional holes (diameter $3 \mathrm{~cm}$ ) in the cylinder wall, which were covered with thrips-proof nylon gauze (pore size $64 \mu \mathrm{m}$ ).

Ten one-week old adult western flower thrips females and two males were selected from a synchronized rearing unit and transferred into a clean Eppendorf tube ( $2 \mathrm{ml})$ using a fine hairbrush. The Eppendorf tube was fixed on the petiole of the bean plant and afterwards 
opened to allow the adults to crawl/fly out of the tube and infest the plant. The edge between cylinder and pot was sealed with parafilm to prevent thrips from escaping. Thrips were allowed to feed and to lay eggs on the plants, and on the fifth day when L1 had hatched, two female Orius were introduced using the same delivery technique as with thrips. On the eighth day when L2 should start descending to the soil for pupation (Berndt et al. 2004), the microcosm was cautiously opened to avoid any escape of thrips, and the soil treatments were quickly applied such that the L2 stage targeted here didn't escape. For NeemAzal-T application $0.6 \mathrm{ml}$ of the basic solution diluted in $100 \mathrm{ml}$ de-ionized water was drenched to the soil. The EPN suspension of about 80,500 infective juveniles (IJ) in $25 \mathrm{ml}$ of de-ionized water was also drenched using a Pasteur pipette and five minutes later the soil surface was further irrigated with another $25 \mathrm{ml}$ of distilled water for better percolation of the nematodes to lower soil layers where the western flower thrips pupate. For EPF, the whole conidia suspension $(100 \mathrm{ml})$ was applied to each pot, which ensured a total wetting to field capacity of the upper soil layer that should be passed by the descending thrips larvae.

A blank treatment with only de-ionized water was set up as a control since pre-tests showed no significant differences between the blanks of the compounds used and the water control. Twelve days after the introduction of the western flower thrips adults, the cylinders were removed and the bean plants were cut off. Orius were found to be still active on the canopy but barely any thrips adults. To assess efficacy of the treatments, the number of emerging western flower thrips was recorded for seven days using an emergence trap as described in Otieno et al. (2016). In brief the emergence traps consisted of an inverted pot of the same size as the one used for the substrate in the microcosm and tightly fitting on the substrate. The positively phototactic emerging thrips were attracted to a light exposed hole on top of this elector unit and guided into an adjusted Eppendorf tube (trap).

All experiments were conducted in a climate chamber (Johnson Controls GmbH, Mannheim, Germany). The conditions were $23 \pm 2{ }^{\circ} \mathrm{C}, 50-60 \% \mathrm{RH}$ and 16:8 L: D photoperiod. 
Experiment 1: Basic treatments and combinations: The full list of treatments and dosages used is shown in supplementary table S1. A completely randomized design with fifteen replicates per treatment was used in all experiments. Additionally, in EPF treatments a test for late mycosis was performed. Adult thrips emerging from treatments with EPF were incubated at $25{ }^{\circ} \mathrm{C}$ in $55 \mathrm{~mm}$ diameter Petri dishes filled with a $5 \mathrm{~mm}$ plaster of Paris: charcoal $(9: 1)$ layer overlaid by a Whatman filter paper of the same diameter. $1.5 \mathrm{ml}$ of sterile water was added to maintain high humidity. Most (> 90\%) of the incubated adults died after two days, and the cadavers of these specimens were examined under a binocular microscope for spores and hyphae on their surface for identification of the suspended EPF and to confirm mycosis as the cause of death.

Experiment 2: Two densities of Orius: To assess density dependent variation in Orius efficacy, one vs. two adult Orius were released in different combinations with EPF, EPN and azadirachtin using the experimental procedure as described above, and the soil treatments were applied as in the previous experiment.

Experiment 3: Efficacy of Orius targeting different larval stages of western flower thrips: In an additional setup, Orius was released on the fifth and eighth day after introduction of western flower thrips adults to target the L1 and L2 stages of western flower thrips, respectively. The soil treatments and combinations with EPF, EPN and Neem were applied as in experiment 1.

Biostatistical analysis: In all experiments, the number of emerging thrips per pot was modelled as Poisson counts in a generalized linear model (McCullagh and Nelder 1989) with a logarithmic link function and overdispersion (“quasi-Poisson”). Analysis of deviance $F$ tests were performed for testing overall effects (Faraway 2006 p. 147) and they were all highly significant (supplementary table S2). Treatment means were compared using all pair-wise contrasts (Tukey) of the generalized linear model (GLM) parameters at a family-wise type I error rate of $5 \%$. 
Interactions of treatments applied as combinations were evaluated as described for a very similar experimental setup in Otieno et al. (2016). Null hypotheses of additivity were formulated as linear combinations of GLM parameters in a way that they reflected the mixing ratios shown in Table S1. Combinations that deviated significantly $(\mathrm{p}<0.05)$ from additivity were judged as synergistic if fewer thrips emerged from soil than expected under additivity, or otherwise as antagonistic. All data were analyzed using $\mathrm{R}$ version 3.1.3 (R Core Team 2016).

\section{Results}

Experiment 1: Single treatments: All treatments were significantly superior to the control according to the Tukey of GLM parameters at a family-wise 5\% level $(\mathrm{p}<0.001$, and test statistics $4.71 \leq \mathrm{z} \leq 8.10$, Tukey). Emergence of adult western flower thrips was reduced on average by $45-74 \%$ compared to the control group, with Orius being the most efficient single treatment (Fig. 1), although there were no significant differences except between Orius and M. anisopliae ICIPE-69 ( $p=0.002, \mathrm{z}=4.18)$.

Double combinations: All Orius-based double combinations revealed significantly higher efficacies than other double combinations without Orius $(\mathrm{p}<0.001$ for every pairwise comparison, 3.89 $\leq \mathrm{z} \leq 5.51$, Tukey) (Fig. 1). Orius based combinations caused 89-97\% reduction in emergence while those that did not include Orius ranged between 62 and 69\% reduction in emergence. The most efficient among the double combinations was Orius + Neem with $97 \%$ reduction.

Triple combinations: Triple combinations showed consistently high performance of Oriusbased combinations, the reduction in thrips emergence ranged between 84 and $96 \%$. The Tukey test showed highly significant differences between Orius-based triple combinations 
and Neem $+\mathrm{EPF}+\mathrm{EPN}(\mathrm{p}<0.01,4.0 \leq \mathrm{z} \leq 5.41$, Tukey). The latter only resulted in $65 \%$ reduction in adult emergence.

Mycosis: The total fungal efficacy was realized when adult thrips that succumbed after emergence from the delayed effect of mycosis were taken into consideration as well. There were no significant differences in the number of cadavers which were not infested by the fungi between all EPF based treatments $(\mathrm{p} \geq 0.066,0.1 \leq \mathrm{z} \leq 3.18$, Tukey). The results ranged from EPF (applied singly) where 93\% total mortality was recorded, to Orius + EPF + EPN where more than $99 \%$ kill was achieved when late mycosis was taken into consideration (Fig. 2).

Interaction effects: Most combined treatments resulted in additive effects (Table 1). However, the double combination Orius + Neem and the triple combination Orius $+\mathrm{EPF}+\mathrm{EPN}$ allowed significantly fewer emergences than would have been expected under the assumption of additivity ( $\mathrm{p}=0.013, \mathrm{z}=2.470$ and $\mathrm{p}=0.004, \mathrm{z}=2.860$ respectively), hence synergistic effects can be assumed (Table 1).

Experiment 2: Two densities of Orius (1 or 2 adults): All treatments showed additional reduction in average western flower thrips emergence when two predators were introduced instead of one to a microcosm, although the differences were not always significant. Combinations with a single predator caused on average between 76 and $88 \%$ reduction while those with two predators resulted in $86-96 \%$ reduction (Fig. 3). However, when Orius was introduced alone a significant difference between one Orius (76\% reduction) and two Orius (96\% reduction) $(\mathrm{p}=0.039, \mathrm{z}=3.43$, Tukey) could be observed. In combined treatments there was no significant difference between introducing one or two adult Orius $(\mathrm{p} \geq 0.57$, $0.64 \leq \mathrm{Z} \leq 2.29)$.

Experiment 3: Introduction of Orius to target different larval stages of western flower thrips: Targeting the L1 stage of western flower thrips was always significantly more successful than targeting the L2 for every treatment. For example, Orius alone resulted in $98 \%$ reduction 
when targeting the L1 and only $78 \%$ when targeting the L2 stage of western flower thrips ( $\mathrm{p}<0.001, \mathrm{z}=6.4$, Tukey). Generally, combinations with Orius targeting the L1 stage of western flower thrips resulted in 96-98\% average reduction in emergence with no significant differences amongst them ( $\mathrm{p} \geq 0.69,0.11 \leq \mathrm{z} \leq 2.09$, Tukey). (Fig. 4). On the other hand, combinations with Orius targeting the L2 stage of western flower thrips caused average reduction of $71-89 \%$. Significant differences were only recorded between Orius + EPF_L2 (the lowest performer) and Orius + EPN_L2 (p<0.001, z=4.39 Tukey) and Orius + EPN + Neem_L2 ( $p<0.001, \mathrm{z}=5.51$ Tukey).

\section{Discussion}

Regarding the effect of single treatments on western flower thrips in experiment 1, Orius was the most efficient. The results of soil application of $M$. anisopliae ICIPE-69, NeemAzal-T and S. carpocapsae as single treatments were consistent with earlier findings by Otieno et al. (2016). The slightly better performance of EPN compared to EPF could be explained by the fact that infective juveniles have the ability to find their host actively and are therefore better suited to locate the cryptic pupal stages of western flower thrips than conidia of EPF whose success depends on contact by chance when thrips move in the soil or by passive distribution with water in the soil (Williams et al. 2013). Overall effect of EPF was substantially increased when thrips mortality due to late mycosis was taken into consideration. The larvae migrating into the soil might have acquired sub-lethal infection (relatively few conidia) but as mortality is dose related, infection took longer to develop; therefore, more individuals survived through to adult stages but succumbed thereafter (Ansari et al. 2008).

Efficacy against western flower thrips was significantly improved in combined treatments compared to single treatments. In particular, Orius-based double and triple combinations performed significantly better than their non-Orius-based counterparts. Comparable results were obtained by Rahman et al. (2011), in other studies, Down et al. (2009) used $O$. 
laevigatus to disseminate conidia of EPFs to control aphids, whiteflies and thrips, indicating that Orius is not affected by these pathogens. Studies with other sucking pests for instance the application of Beauveria bassiana and neem together increased the mortality of B. tabaci (Islam et al. 2010, Islam and Omar 2012). In contrast, combined application of M. anisopliae and Neoseiulus cucumeris (Oudemans) releases did not further reduce the density of adult western flower thrips compared with sole application of $M$. anisopliae or $N$. cucumeris (Nyasani et al. 2015).

An important aspect of combined treatments is the direction and intensity of the resulting joint efficacy. It is desired that combining different control agents may result in simply additive or better synergistic interactions. On the other hand, if control agents could impair each other, reduced total efficacies could result. In our studies, we found only positive interaction within all treatment combinations, most of them with additive properties, but (Orius + Neem) and $($ Orius $+\mathrm{EPF}+\mathrm{EPN})$ combinations showed clear synergistic responses.

Throughout the experiments, combined application of azadirachtin with EPNs or EPF resulted in increased efficacy against western flower thrips. Ebssa et al. (2006) reported that the use of EPNs together with the foliar-dwelling $N$. cucumeris provided better control ( $83 \%$ mortality) as compared to individual releases of natural enemies.

The underlying mechanisms of these synergistic interactions are unclear, but it is postulated that one agent may stress or alter the behaviour like feeding or movement of the target pest making it more susceptible to the other control agents. For example, $M$. anisopliae infected insects may be less mobile which gives EPNs more time to penetrate the host (Ansari et al. 2004). Alternatively, plant-dwelling predators can evoke escape behaviour of the prey, making the prey available for soil-foraging antagonists or biopesticides. Ebssa et al. (2006) noted that foliar-dwelling mites increased the likelihood of thrips falling off the plant onto nematode-treated soil where they were liable to be infected. Azadirachtin weakened the western flower thrips by being a physiological stressor or behavioural modifier, thereby 
predisposing them to the microbes or reducing the defense response of the thrips, making them an easier target for nematodes' penetration and more susceptible to the fungi. The nematode-associated symbionts release toxins that inhibit host immune reactions (Lacey et al. 2001). Such synergies can be exploited to enhance control of pests, while concomitantly reducing the cost of control for growers since each biocontrol agent can be used at a lower dose.

There are contrasting reports concerning the compatibility of azadirachtin and $O$. laevigatus. Biondi et al. (2012) reported that azadirachtin mainly acts as a moulting disruptor and hence cannot affect adult insects and is therefore harmless to the adult predator, and according to Angeli et al. (2005) azadirachtin has no effect on O. laevigatus exposed via direct contact or by ingestion of infected eggs of Ephestia kuehniella (Zeller). Contrastingly, Bonsignore and Vacante (2012) reported that rotenone, NeemAzal-TS (oil formulation of azadirachtin) and $S$. feltiae reduced numbers of $O$. laevigatus and Tedeschi et al. (2001) showed high direct toxicity of neem (azadirachtin oil formulation) to the mirid Macrolophus caliginosus (Wagner). But it should be recognized that in our studies the azadirachtin treatment (soil) and Orius (plant canopy) were spatially divided, thus enabling selectivity even in case of possible contact toxicity.

The number of released predators could be critical for an optimal balance between efficacy and expenditure on the control agent. Therefore, in an additional experiment we checked if the density of the predator could be reduced without impairing its effectiveness. In the single Orius treatment, predation of thrips was significantly higher when two predators were released per microcosm compared to only one. However, the drawback of introducing only one predator was largely compensated for by combined treatments with other biocontrol agents, showing clearly a stabilizing effect of combinations. This improved reliability of combined treatments is of practical importance. 
Another important issue is the timing of application of biocontrol agents. In case of the soildelivered EPNs and EPF as well as drenching of neem, application just before the late L2 descends to the soil ensures the best performance (Premachandra et al. 2003b). In case of predator release, timing is more crucial since target susceptibility and hence predatory success rate can vary greatly with progress in development of the prey. Most often early release of predators is key for successful biocontrol (Cloyd 2009). This work corroborated the need for early releases by showing that introducing Orius to target the L1 was significantly more successful than targeting the L2 stage of western flower thrips. Apart from being able to feed on more juveniles at this stage, it also allowed time for better establishment of the predator, interaction between prey and predator, and therefore good control of thrips (Cloyd 2009).

Further studies should include long term effect of the EPF and azadirachtin on population development of the predator and also, using other Orius spp. with other biocontrol agents to determine if the observation with Orius laevigatus is consistent. We demonstrated that Orius laevigatus is effective in controlling thrips and also suitable to be released in combinations with soil applied azadirachtin and entomopathogens (EPNs and EPF). These combinations resulted in additive and synergistic effects, covering gaps of efficacy and improving the reliability of single agent treatments.

\section{Acknowledgment}

The authors would like to express their gratitude to Trifolio-M GmbH (Lahnau, Germany) for providing NeemAzal-T, e-nema $\mathrm{GmbH}$ (Raisdorf, Germany) for providing Steinernema carpocapsae (Nemastar®), and the International Centre of Insect Physiology and Ecology (icipe) (Nairobi, Kenya) for supplying Metarhizium anisopliae isolate ICIPE-69. The study was supported by a grant from the German Academic Exchange Service (Deutscher Akademischer Austauschdienst-DAAD). 


\section{References}

Angeli G, Baldessari M, Maines R, Duso C (2005) Side-effects of pesticides on the predatory bug Orius laeviagtus (Heteroptera: Anthocoridae) in the laboratory. Biocontrol Sci Technol 15:745-754.

Ansari M, Tirry L, Moens M (2004) Interaction between Metarhizium anisopliae CLO 53 and entomopathogenic nematodes for the control of Hoplia philanthus. Biol Control 31:172180.

Ansari MA, Brownbridge M, Shah FA, Butt TM (2008) Efficacy of entomopathogenic fungi against soil-dwelling life stages of western flower thrips, Frankliniella occidentalis, in plant-growing media. Entomol Exp Appl 127:80-87.

Ansari MA, Shah FA, Whittaker M, Prasaad M, Butt TM (2007) Control of western flower thrips (Frankliniella occidentalis) pupae with Metarhizium anisopliae in peat and peat alternative growing media. Biol Control 40:293-297.

Berndt O, Meyhöfer R, Poehling H-M (2004) The edaphic phase in the ontogenesis of Frankliniella occidentalis and comparison of Hypoaspis miles and Hypoaspis aculeifer as predators of soil-dwelling thrips stages. Biol Control 30:17-24.

Bielza P, Quinto V, Fernandez E, Gravalos C, Contreras J (2007) Genetics of spinosad resistance in Frankliniella occidentalis (Thysanoptera: Thripidae). J Econ Entomol 100:916-920.

Biondi A, Desneux N, Siscaro G, Zappalà L (2012) Using organic-certified rather than synthetic pesticides may not be safer for biological control agents: Selectivity and side effects of 14 pesticides on the predator Orius laevigatus. Chemosphere 87:803-812.

Blaeser P, Sengonca C, Zegula T (2004) The potential use of different predatory bug species in the biological control of Frankliniella occidentalis Pergande (Thysanoptera: Thripidae). J Pest Sci 77:211-219. 
Bonsignore CP, Vacante V (2012) Influences of botanical pesticides and biological agents on Orius laevigatus - Frankliniella occidentalis dynamics under greenhouse conditions. J Plant Prot Res 52:15-23.

Bosco L, Giacometto E, Tavella L (2008) Colonization and predation of thrips (Thysanoptera: Thripidae) by Orius spp. (Heteroptera: Anthocoridae) in sweet pepper greenhouses in Northwest Italy. Biol Control 44:331-340.

Brownbridge M (2006) Entomopathogenic fungi: status and considerations for their development and use in integrated pest management. Recent Res Devel Entomol 5:2758

Buitenhuis R, Shipp JL (2005) Efficacy of entomopathogenic nematode Steinernema feltiae (Rhabditida: Steinernematidae) as influenced by Frankliniella occidentalis (Thysanoptera: Thripidae) developmental stage and host plant stage. J Econ Entomol 98:1480-1485.

Cloyd RA (2009) Western Flower Thrips Frankliniella occidentalis management on ornamental crops grown in greenhouses: Have we reached an impasse ? Pest Technol $3: 1-9$.

Down RE, Cuthbertson AGS, Mathers JJ, Walters KFA (2009) Dissemination of the entomopathogenic fungi, Lecanicillium longisporum and L. muscarium, by the predatory bug, Orius laevigatus, to provide concurrent control of Myzus persicae, Frankliniella occidentalis and Bemisia tabaci. Biol Control 50:172-178.

Ebssa L, Borgemeister C, Poehling HM (2006) Simultaneous application of entomopathogenic nematodes and predatory mites to control western flower thrips Frankliniella occidentalis. Biol Control 39:66-74.

Faraway JJ (2006) Extending the Linear Model with R: Generalized Linear, Mixed Effects and Nonparametric Regression Models. Chapman \& Hall/CRC, Boca Raton, FL. 
Gao Y, Reitz SR, Wang J, Tamez-Guerra P, Wang E, Xu X, Lei Z (2012) Potential use of the fungus Beauveria bassiana against the western flower thrips Frankliniella occidentalis without reducing the effectiveness of its natural predator Orius sauteri (Hemiptera:Anthocoridae). Biocontrol Sci Techn 22:803-812.

Goettel MS, Inglis GD (1997) Fungi: Hyphomycetes, In: Lacey, L. (Ed.) Manual of Techniques in Insect Pathology. Academic Press, San Diego, CA. pp. 213-249.

Herron GA, James TM (2005) Monitoring insecticide resistance in Australian Frankliniella occidentalis Pergande (Thysanoptera: Thripidae) detects fipronil and spinosad resistance. Aus J Entomol 44:299-303.

Holmes ND, Bennison JA, Maulden KA, Kirk WDJ (2012) The pupation behaviour of the western flower thrips, Frankliniella occidentalis (Pergande). Acta Phytopathol Entomol Hungarica 47:87-96.

Islam MT, Castle SJ, Ren S (2010) Compatibility of the insect pathogenic fungus Beauveria bassiana with neem against sweetpotato whitefly, Bemisia tabaci, on eggplant. Entomol Exp 134:28-34.

Islam MT, Omar DB (2012) Combined effect of Beauveria bassiana with neem on virulence of insect in case of two application approaches. J Anim plant Sci 22:77-82.

Jensen SE (2000) Insecticide resistance in the western flower thrips, Frankliniella occidentalis. Integr Pest Manag Rev 5:131-146.

Karanja J, Poehling H-M, Pallmann P (2015) Efficacy and dose response of soil-applied Neem formulations in substrates with different amounts of organic matter, in the control of whiteflies, Aleurodes proletella and Trialeurodes vaporariorum (Hemiptera: Aleyrodidae). J Econ Entomol 108: 1182-1190.

Lacey L, Frutos R, Kaya H, Vail P (2001) Insect pathogens as biological control agents: Do they have a future? Biol Control 21:230-248. 
McCullagh P, Nelder JA (1989) Generalized Linear Models, Second Edition, Chapman \& Hall/CRC, Boca Raton, FL.

Medina P, Smagghe G, Budia F, Tirry L, Vin E (2003) Toxicity and absorption of azadirachtin, diflubenzuron, pyriproxyfen, and tebufenozide after topical application in predatory larvae of Chrysoperla carnea (Neuroptera: Chrysopidae). Environ Entomol 32:196-203.

Mitchell PL, Gupta R, Singh AK, Kumar P (2004) Behavioral and developmental effects of neem extracts on Clavigralla scutellaris (Hemiptera:Heteroptera :Coreidae) and its egg parasitoid, Gryon fulviventre (Hymenoptera : Scelionidae) J Econ Entomol 97:916-923.

Mohan MC, Reddy NP, Devi UK, Kongara R, Sharma HC (2007) Growth and insect assays of Beauveria bassiana with neem to test their compatibility and synergism. Biocontrol Sci Techn 17:1059-1069.

Niassy S, Maniania NK, Subramanian S, Gitonga LM, Mburu DM, Masiga D, Ekesi S (2012) Selection of promising fungal biological control agent of the western flower thrips Frankliniella occidentalis (Pergande). Lett Appl Microbiol 54: 487-493.

Nyasani JO, Subramanian S, Poehling H-M, Maniania NK, Ekesi S, Meyhöfer R (2015) Optimizing western flower thrips management on French beans by combined use of beneficials and imidacloprid. Insects 6:279-296.

Otieno JA, Pallmann P, Poehling H-M (2016). The combined effect of soil-applied azadirachtin with entomopathogens for integrated management of western flower thrips. J Appl Entomol 140:174-186.

Pozzebon A, Boaria A, Duso C (2015) Single and combined releases of biological control agents against canopy- and soil-dwelling stages of Frankliniella occidentalis in cyclamen. BioControl 60:341-350.

Premachandra WTSD, Borgemeister C, Berndt O, Ehlers UE, Poehling H-M (2003b) Laboratory bioassays of virulence of entomopathogenic nematodes against soil- 
inhabiting stages of Frankliniella occidentalis Pergande (Thysanoptera: Thripidae). Nematology 5:539-547.

Premachandra, WTSD, Borgemeister C, Berndt O, Ehlers RU, Poehling H-M (2003a) Combined releases of entomopathogenic nematodes and the predatory mite Hypoaspis aculeifer to control soil-dwelling stages of western flower thrips Frankliniella occidentalis. BioControl 48:529-541.

R Core Team (2016) R: A Language and Environment for Statistical Computing, R Foundation for Statistical Computing, Vienna, Austria. http://www.R-project.org/.

Rahman T, Spafford H, Broughton S (2011) Single versus multiple releases of predatory mites combined with spinosad for the management of western flower thrips in strawberry. Crop Prot 30:468-475.

Reitz SR, Gao YL, Lei ZR (2011) Thrips: Pests of concern to China and the United States. Agric Sci China 10:867-892.

Sanchez JA, Alcazar A, Lacasa A, Llamas A, Bielza P (2000) Integrated pest management strategies in sweet pepper plastic houses in the Southeast of Spain. IOBC/WPRS Bull 23: $21-30$.

Shapiro-Ilan DI, Cottrell TE, Mizell RF, Horton DL, Behle RW, Dunlap CA (2010) Efficacy of Steinernema carpocapsae for control of the lesser peach tree borer, Synanthedon pictipes : Improved above ground suppression with a novel gel application. Biol Control $54: 23-28$.

Shipp JL, Wang K (2003) Evaluation of Amblyseius cucumeris (Acari: Phytoseiidae) and Orius insidiosus (Hemiptera: Anthocoridae) for control of Frankliniella occidentalis (Thysanoptera: Thripidae) on greenhouse tomatoes. Biol Control 28: 271-281.

Silveira LCP, Bueno VHP, Van Lenteren JC (2004) Orius insidiosus as biological control agent of thrips in greenhouse chrysanthemums in the tropics. Bull Insectol 57:103-109. 
Skinner M, Gouli S, Frank, CE, Parker BL, Kim JS (2012) Management of Frankliniella occidentalis (Thysanoptera: Thripidae) with granular formulations of entomopathogenic fungi. Biol Control 63:246-252.

Steiner MY, Spohr LJ, Goodwin S (2011) Relative humidity controls pupation success and dropping behaviour of western flower thrips, Frankliniella occidentalis (Pergande) (Thysanoptera: Thripidae). Aust J Entomol 50:179-186.

Tedeschi R, Alma A, Tavella L (2001) Side-effects of three neem (Azadirachta indica A. Juss) products on the predator Macrolophus caliginosus Wagner (Heteroptera: Miridae). J Appl Entomol 125:397-402.

Thoeming G, Draeger G, Poehling H-M (2006) Soil application of azadirachtin and 3tigloyl-azadirachtol to control western flower thrips, Frankliniella occidentalis (Thysanoptera: Thripidae): translocation and persistence in bean plants. Pest Manag Sci 62:759-767.

Weintraub PG, Pivonia S, Steinberg S (2011) How many Orius laevigatus are needed for effective western flower thrips, Frankliniella occidentalis, management in sweet pepper? Crop Prot 30:1443-1448.

Williams CD, Dillon AB, Harvey CD, Hennessy R, Namara LM, Griffin CT (2013) Control of a major pest of forestry, Hylobius abietis, with entomopathogenic nematodes and fungi using eradicant and prophylactic strategies. Forest Ecol Manag 305:212-222.

Xu X, Borgemeister C, Poehling H-M (2006) Interactions in the biological control of western flower thrips Frankliniella occidentalis (Pergande) and two-spotted spider mite Tetranychus urticae Koch by the predatory bug Orius insidiosus (Say) on beans. Biol Control 36:57-64. 
Table 1: Evaluation of treatment combinations: estimated percent deviations from additivity with $95 \%$ confidence intervals, p-values, and conclusions about interactions based on quasiPoisson GLM analysis.

\begin{tabular}{|c|c|c|c|c|}
\hline $\begin{array}{l}\text { Treatment } \\
\text { combination }\end{array}$ & $\begin{array}{c}\text { Estimated \% deviation } \\
\text { from additivity }\end{array}$ & $\begin{array}{c}\text { 95\% confidence } \\
\text { interval }\end{array}$ & p-value & Interaction \\
\hline $\mathrm{EPF}+\mathrm{EPN}$ & +30.3 & $-2.6 ;+74.4$ & 0.075 & Additive \\
\hline Neem + EPF & +29.2 & $-4.6 ;+75.1$ & 0.098 & Additive \\
\hline Neem + EPN & +25.5 & $-9.7 ;+74.5$ & 0.177 & Additive \\
\hline Orius + EPF & +68.4 & $-11.6 ;+220.8$ & 0.113 & Additive \\
\hline Orius + EPN & -6.8 & $-49.5 ;+71.9$ & 0.821 & Additive \\
\hline Orius + Neem & +229.4 & $+27.9 ;+748.2$ & 0.014 & Synergistic \\
\hline $\mathrm{Neem}+\mathrm{EPF}+\mathrm{EPN}$ & +27.2 & $-5.1 ;+70.6$ & 0.108 & Additive \\
\hline Orius + EPF + EPN & +259.6 & $+49.6 ;+764.4$ & 0.004 & Synergistic \\
\hline Orius+EPF + Neem & -9.0 & $-48.0 ;+59.1$ & 0.741 & Additive \\
\hline Orius+EPN + Neem & +57.2 & $-22.1 ;+217.4$ & 0.207 & Additive \\
\hline
\end{tabular}




\section{Legend of Figures}

Fig. 1 Average number of emerging adults of western flower thrips after seven days (mean + SD) in single and combined treatments using Orius laevigatus, NeemAzal-T solution (1\% azadirachtin A), Metarhizium anisopliae ICIPE-69 (Entomopathogenic fungi-EPF) and Steinernema carpocapsae (Entomopathogenic nematode-EPN), grouped into single, double and triple treatments. Treatments sharing no common letters are significantly different at a multiple type I error level of 5\% (quasi-Poisson analysis and Tukey).

Fig. 2 Average number of emerging adults of western flower thrips after seven days (mean + SD) (white columns) and adults not infested by mycosis in Metarhizium anisopliae ICIPE-69 based treatment combinations (black columns). Treatments sharing no common letters are significantly different at a multiple type I error level of 5\% (quasi-Poisson analysis and Tukey). NB/Letters refer to comparisons between the combinations of treatments and emerging/infested.

Fig. 3 Average number of emerging adults of western flower thrips after seven days (mean + SD) when one (Orius_1) or two (Orius_2) adults of Orius laevigatus were introduced on the plants in combination with NeemAzal-T solution (1\% azadirachtin A), Metarhizium anisopliae ICIPE-69 (EPF) and Steinernema carpocapsae (EPN) applied to the soil. Treatments sharing no common letters are significantly different at a multiple type I error level of 5\% (quasi-Poisson analysis and Tukey).

Fig. 4 Average number of emerging adults of western flower thrips after seven days (mean + SD) when Orius laevigatus were introduced on the plants to target larval stages 1 (L1) and 2 (L2) in combinations soil treatments by NeemAzal-T solution (1\% azadirachtin A), Metarhizium anisopliae ICIPE-69 (EPF) and Steinernema carpocapsae (EPN). Treatments sharing no common letters are significantly different at a multiple type I error level of 5\% (quasi-Poisson analysis and Tukey). 


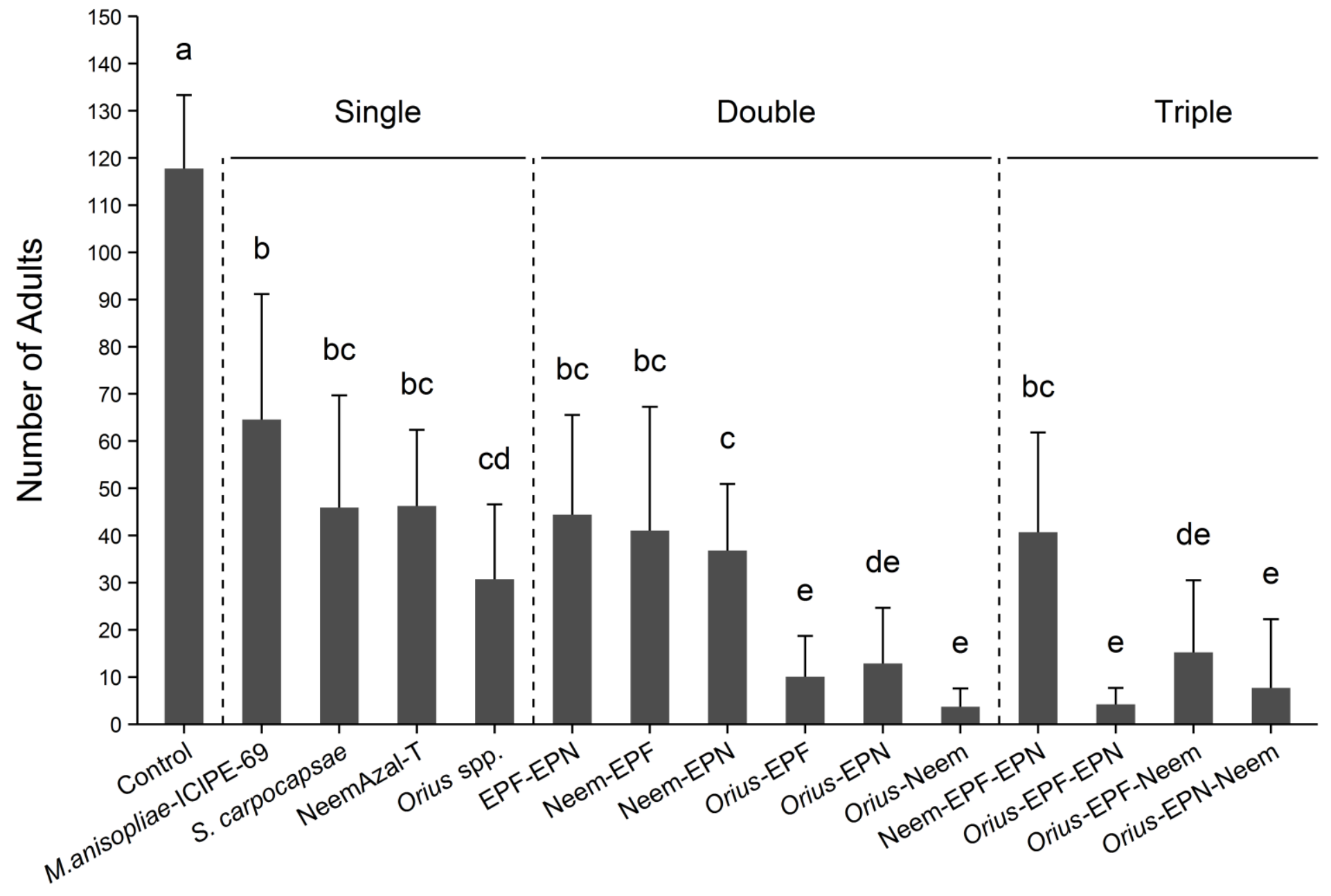

Fig. 1 


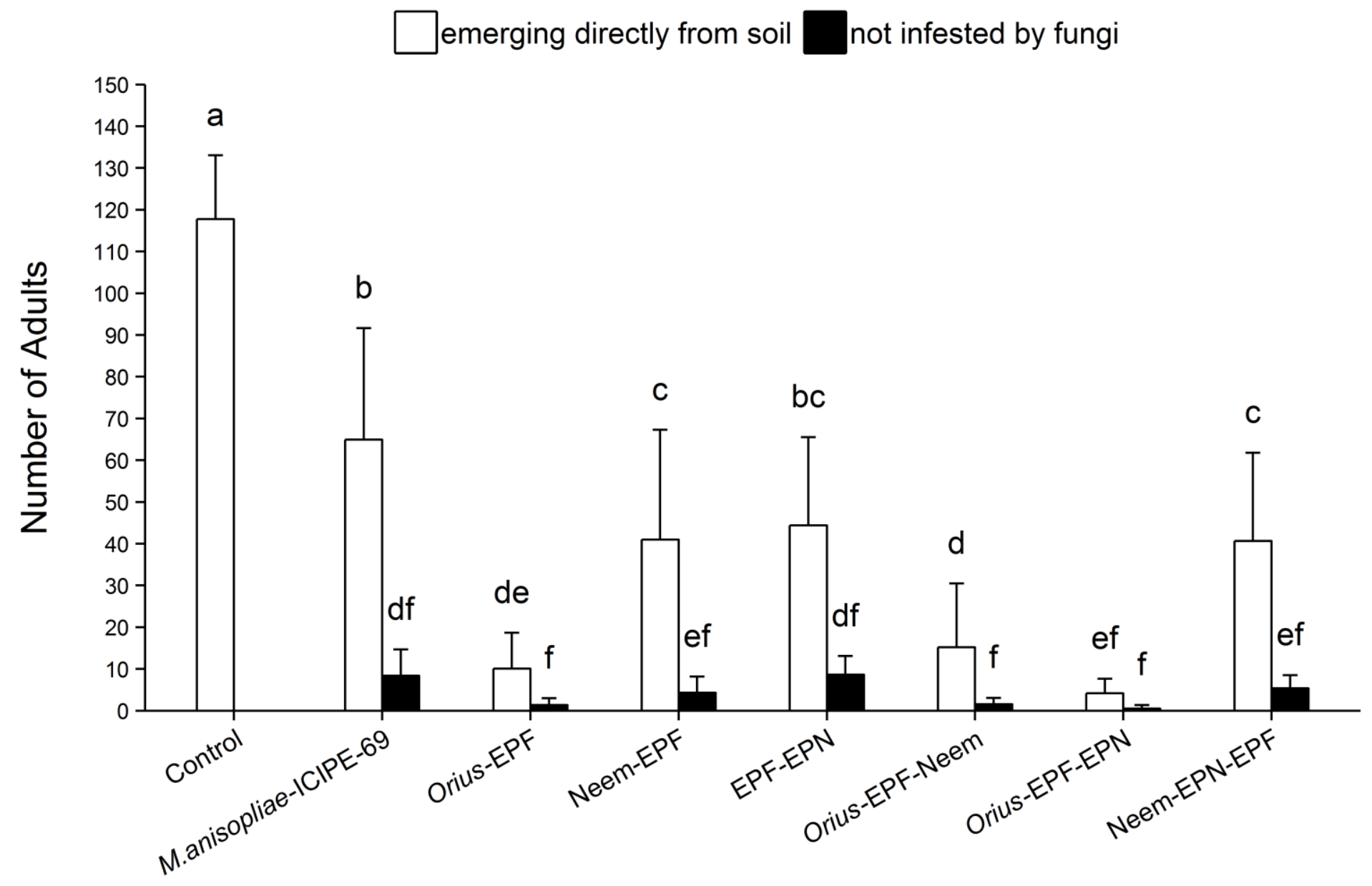

Fig. 2 


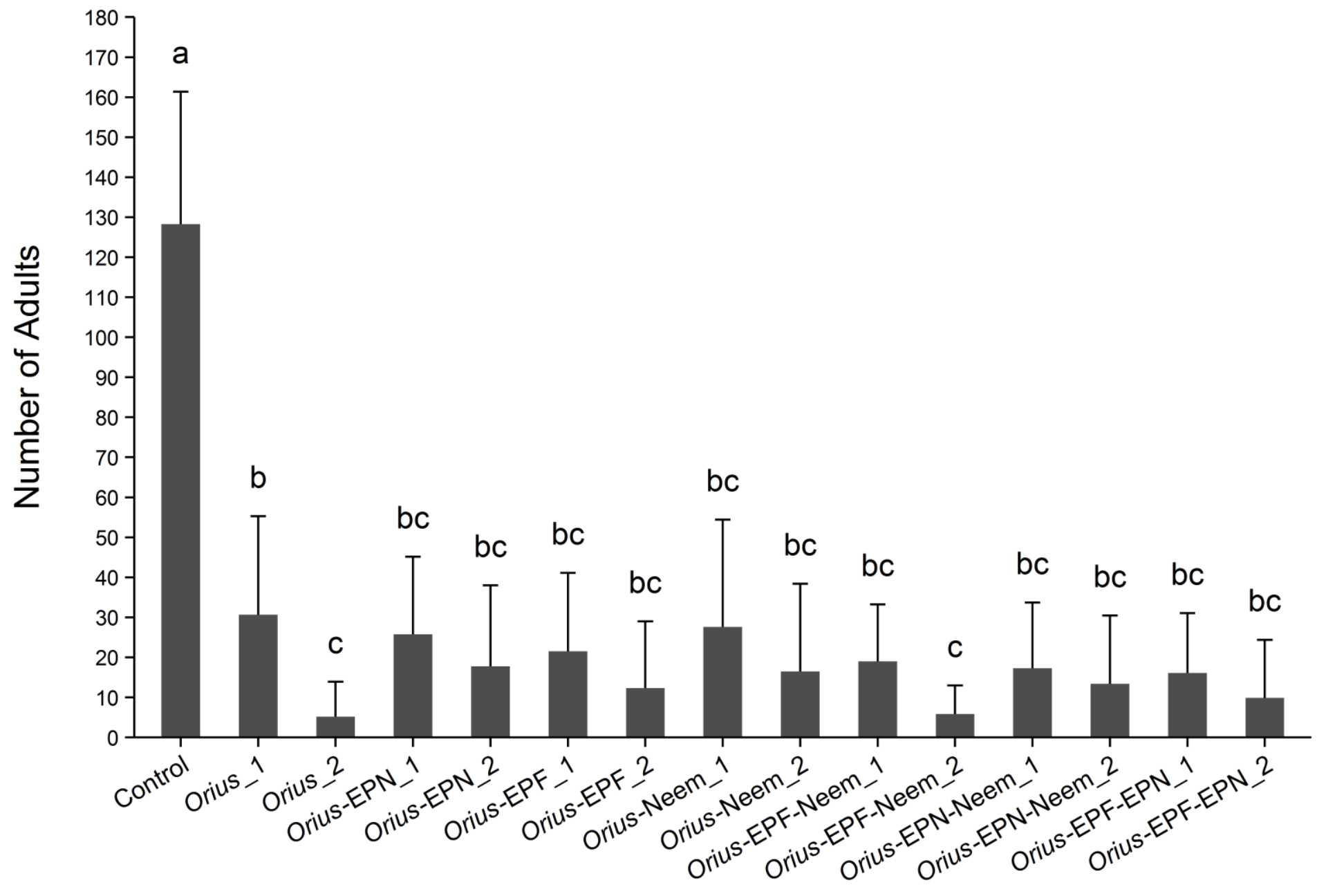

Fig. 3 


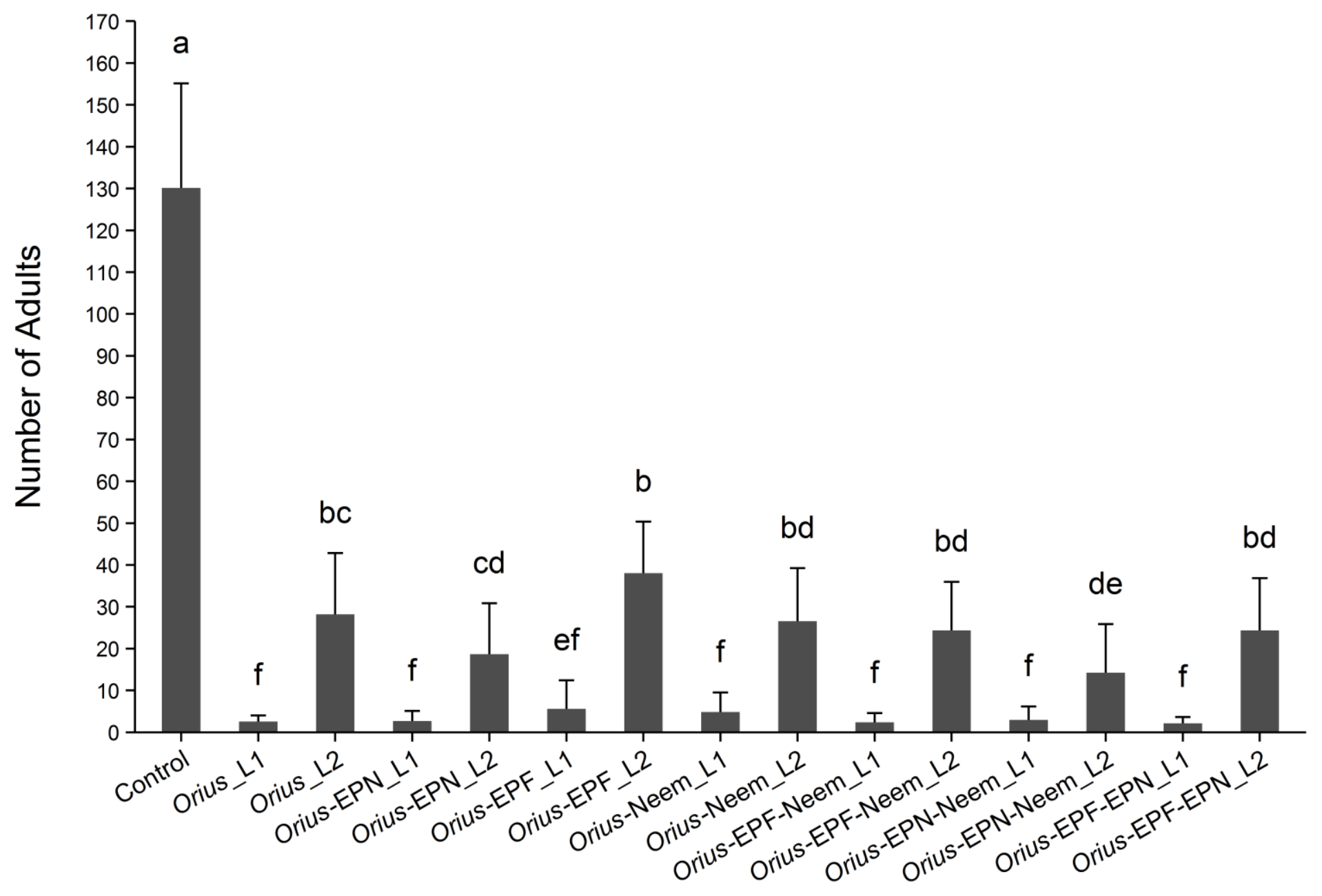

Fig. 4 
Table S1: Single and combined treatments identified by Orius laevigatus released in the canopy and soil treatments given as amount of active compounds/pot (600g of soil) and percentages (relative to the single treatment doses).
Treatment (s)
Canopy
Soil treatments

treatments

$\begin{array}{llll}\text { O. laevigatus } & \text { M. anisopliae- } & \text { NeemAzal-T } & \text { S. carpocapsae } \\ \text { (Orius) } & \text { ICIPE (EPF) } & \text { (Neem) } & \text { (EPN) }\end{array}$

\section{A Single treatments}

O. laevigatus

M. anisopliae (EPF)

NeemAzal-T (Neem)

S. carpocapsae (EPN)
2 adults

$10^{7}$ conidia

$6 \mathrm{mg} \mathrm{AZA**}$

80435 IJ*

$\left(400 \mathrm{IJ} / \mathrm{cm}^{2}\right)$

B Double combinations - (Soil treatments as \% of single treatment used - see A)

\begin{tabular}{|c|c|c|c|c|}
\hline $\mathrm{EPF}+\mathrm{EPN}$ & - & $(67 \%)$ & & $(33 \%)$ \\
\hline $\mathrm{EPF}+\mathrm{Neem}$ & - & $(40 \%)$ & $(60 \%)$ & - \\
\hline $\mathrm{Neem}+\mathrm{EPN}$ & - & & $(75 \%)$ & $(25 \%)$ \\
\hline Orius + EPF & 2 adults & $(100 \%)$ & & \\
\hline Orius + EPN & 2 adults & - & $(100 \%)$ & - \\
\hline Orius + Neem & 2 adults & - & - & $(100 \%)$ \\
\hline
\end{tabular}

C Triple combinations- (Soil treatments as \% of single treatment used - see A

\begin{tabular}{ccccc}
\hline EPF + Neem + EPN & - & $(33 \%)$ & $(50 \%)$ & $(17 \%)$ \\
Orius + EPF+EPN & 2 adults & $(67 \%)$ & - & $(33 \%)$ \\
Orius + EPF+Neem & 2 adults & $(40 \%)$ & $(60 \%)$ & - \\
Orius + EPN+Neem & 2 adults & & $(75 \%)$ & $(25 \%)$
\end{tabular}

*IJ = Infective juveniles; $* * A Z A=$ Azadirachtin 
Table S2: Summary of the results of the analysis of deviance F-tests $(\mathrm{P}=\mathrm{p}$-value, $\mathrm{F}=$ test statistic, $\mathrm{df}_{1}=$ numerator degrees of freedom, $\mathrm{df}_{2}=$ denominator degrees of freedom)

\begin{tabular}{llll}
\hline Experiments & P-value (p) & F-test statistics (F) & Degrees of freedom \\
& & (df)
\end{tabular}

\begin{tabular}{|c|c|c|c|}
\hline All treatments & $\mathrm{P}<10^{-16}$ & $\mathrm{~F}=35.27$ & $\mathrm{df}_{1}=14, \mathrm{df}_{2}=210$ \\
\hline Mycosis & $\mathrm{P}<10^{-16}$ & $\mathrm{~F}=117.82$ & $\mathrm{df}_{1}=14, \mathrm{df}_{2}=225$ \\
\hline 1 or 2 Orius adults & $\mathrm{P}<10^{-16}$ & $\mathrm{~F}=108.45$ & $\mathrm{df}_{1}=15, \mathrm{df}_{2}=210$ \\
\hline Orius targeting & $\mathrm{P}<10^{-16}$ & $\mathrm{~F}=371.31$ & $\mathrm{df}_{1}=15, \mathrm{df}_{2}=210$ \\
\hline larval stages 1 or 2 & & & \\
\hline
\end{tabular}

